\title{
Analisis Pengukuran Daya Saing Destinasi Wisata Berbasis Tourism and Travel Competitiveness Index
}

\section{Analysis of Tourism Destination Competitiveness Measurement Based on Tourism and Travel Competitiveness Index}

\author{
Yuviani Kusumawardhani ${ }^{1)}$ \\ ${ }^{1)}$ Program S1 Usaha Perjalanan Wisata, Sekolah Tinggi Pariwisata Bogor
}

19 November 2019

\begin{abstract}
Porter's theory of international competitiveness departsfrom his belief that classical economic theory that explains comparative advantage is inadequate. A country's competitiveness is determined by the ability of industries to innovate and improve their capabilities. Tourism is currently the star for countries to improve their performance. The Travel and Tourism Competitiveness Index can provide support for countries that want to improve their tourismcompetitiveness. Literature study in a joumal entitled "Measuring Competitiveness Objectives: Application of the Competitiveness Index for Travel and Tourism (2007)" can be a benchmark for measuring Indonesia's tourism power. The advantages of Indonesian tourism so far are still based on the low price factor, but the low price factor is an effective competitiveness factor. This makes Indonesia need to improve other factors that can become more effective competitiveness factors, such as ICT Readiness, Air Transportation Infrastructure, Environmental Sustainability, Land and Port Infrastructure, and Tourist Services Infrastructure.
\end{abstract}

Keywords: Competitiveness, Tourist Destinations, TTCI, Tourism

\begin{abstract}
ABSTRAK
Teori Porter tentang daya saing nasional berangkat dari keyakinannya bahwa teori ekonomi klasik yang menjelaskan tentang keunggulan komparatif tidak mencukupi. Daya saing suatu negara ditentukan oleh kemampuan industri melakukan inovasi dan meningkatkan kemampuannya. Pariwisata saat ini menjadi primadona bagi negara-negara untuk meningkatkan perekonomiannya. Travel and Tourism Competitiveness Index dapat memberikan gagasan bagi negara-negara yang ingin meningkatkan daya saing pariwisatanya. Studi kepustakaan pada jurnal yang berjudul "Measuring Destination Competitiveness: An Application of the Travel and Tourism Competitiveness Index (2007)" dapat menjadi sebuah tolak ukur bagaimana mengukur daya saing pariwisata Indonesia. Keunggulan pariwisata Indonesia selama ini masih bertopang pada faktor harga yang murah, namun faktor harga murah pada kenyataannya bukan menjadi salah satu faktor daya saing yang efektif. Hal ini membuat Indonesia perlu melakukan peningkatan pada faktor lainnya yang dapat menjadi faktor daya saing yang lebih efektif, seperti pada ICT Readiness, Air Transportation Infrastructure, Environmental Sustainability, Ground and Port Infrastructure, dan Tourist Service Infrastructure.
\end{abstract}

Kata Kunci: Daya Saing, Destinasi Wisata, TTCI, Pariwisata 


\section{PENDAHULUAN}

Globalisasi yang terjadi saat ini menggiring pariwisata yang bersifat massal berubah menjadi bentuk-bentuk pariwisata yang berpusat di dalamfleksibelitas, segmentasi, dan integrasi diagonal. Sektor pariwisata saat ini menjadi sektor unggulan bagi pembangunan sebuah negara. Industri Pariwisata adalah sebuah industri yang dimana terdapat banyak para stakeholder yang terlibat dan memberikan pengaruh dan manfaat dalam berbagai aspek kehidupan manusia dan bidang ilmu pengetahuan, budaya, serta teknologi. Pariwisata bagi negara maju sudah menjadi leading sector. Kebutuhan orang akan perjalanan wisata untuk mendapatkan relaksasi, rasa ingin tahu, pengalaman, pengetahuan, dan hiburan sudah menjadi kebutuhan. Dampak dari rutinitas kegiatan sehari-hari ini adalah melepaskan kepenatan dan kejenuhan dengan berwisata.

Pariwisata dapat dikategorikan kedalam kelompok industri terbesar dunia, karena menyumbangkan sekitar $8 \%$ untuk ekspor barang dan jasa. Pariwisata pun menjadi penyumbang terbesar dalam perdagangan internasional. Prospek pariwisata ke depan sangat menjanjikan bahkan dapat memberikan peluang besar, terutama ketika melihat angka perkiraan jumlah wisatawan internasional (inbound tourism) berdasarkan perkiraan WTO yakni 1,602 milyar orang pada tahun 2020 yang mampu menciptakan pendapatan dunia sebesar USD 2 triliun pada tahun 2020. Oleh karenaitu, pemanfaatan peluang harus dilakukan melalui pendekatan re-positioning daya saing destinasi pariwisata dimulai dari iklim investasi, promosi, pembuatan produk pariwisata, penyiapan jaringan pemasaran internasional, dan penyiapan sumber daya manusia yang berkualitas. Hal yang demikian perlu disiapkan untuk memenuhi standar internasional sehingga dapat lebih kompetitif. World Economic Forum adalah sebuah lembaga terpercaya yang berpusat di Geneva, Swiss. Lembaga ini mengeluarkan sebuah laporan yang dikenal dengan Travel and Tourism Competitiveness Index dan menjadi referensi bagi 136 negara di dunia untuk memeringkat negara-negara yang memiliki daya saing pariwisata dengan kriteria yang jelas. Terdapat 14 pilar yang dikalibrasi dengan standar yang sama oleh Travel \& Tourism Competitiveness Index (TTCI).
Berdasarkan hasil laporan TTCI ini, negaranegara dapat mengetahui sudah seberapa jauh negaranya memiliki daya saing pariwisata, selain itu mereka juga dapat mengetahui faktor mana yang menjadi titik lemah daya saing pariwisata sehingga mereka dapat segera memperbaikinya.

Perkembangan pariwisata global juga turut mempengaruhi pariwisata Indonesia. Indonesia berdasarkan hasil Travel and Tourism Competitiveness Index 2017 berada peringkat ke-42, naik sebanyak 8 peringkat dari periode tahun sebelumnya. Indonesia memiliki peluang untuk menjadikan destinasi wisata yang berada di Indonesia dapat menarik minat para wisatawan baik lokal maupun mancanegara. Destinasi wisata Indonesia diharapkan dapat menjadi salah satu destinasi penting di mata dunia. Pertumbuhan wisatawan mancanegara yang datang ke Indonesia dari tahun ke tahun semakin meningkat. Data statistik kunjungan wisatawan mancanegara dapat dilhat pada gambar 1 .

\section{Jumlah Kunjungan Wisatawan Mancanegara Tahun 2015-2017}

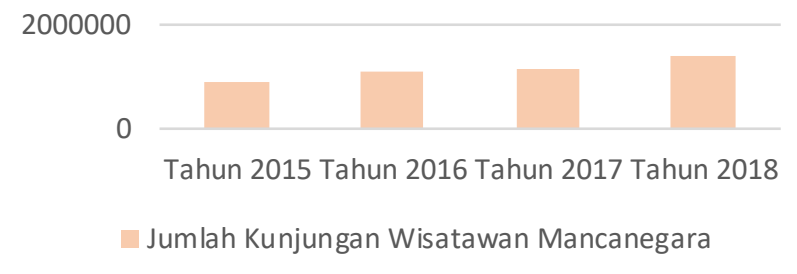

Gambar 1. Jumlah Kunjungan Wisatawan Mancanegara Tahun 2015-2018

Sumber: (BPS 2018)

Sektor pariwisata di Indonesia saat ini menjadi penyumbang terbesar kedua pada Produk Domestik Bruto (PDB). Hal ini membuktikan bahwa pariwisata Indonesia pun sedang mengalami kemajuan yang cukup pesat. Daya saing adalah produktivitas yang didefinisikan sebagai output yang dihasilkan oleh suatu negara. Daya saing sebuah negara dapat dicapai dari akumulasi dayasaing strategis setiap sektor yang terkait di dalamnya (Porter 2008). Menurut World Economic Forum, daya saing nasional adalah kemampuan perrekonomian nasional untuk mencapai pertumbuhan ekonomi yang tinggi dan berkelanjutan. Daya saing ditentukan oleh keunggulan bersaing suatu negara dan sangat bergantung pada 
tingkat sumber daya relatif yang dimilikinya atau yang disebut keunggulan kompetitif. Oleh karenanya, destinasi wisata yang dimiliki Indonesia harus memiliki daya tarik dan daya saing secara global. Berdasarkan Data Tourism and Travel Competitiveness Index pada tahun 2011 Indonesia menduduki peringkatke-74 dan tahun 2015 menduduki peringkat ke-42. Hal ini menggambarkan bahwa, Indonesia sudah cukup baik dalam meningkatkan daya saing pariwisatanya namun perlu mengoptimalkan daya saing pariwisatanya secara simultan.

Keunggulan pariwisata Indonesia masih bertopang pada faktor harga yang murah ketika seseorang melakukan perjalanan wisata. Harga yang murah terkadang merepresentasikan produk wisata yang rendah, sehingga hal inilah yang menjadikan Indonesia masih tertinggal dari negara-negara tetangganya. Kasali (2005) mengungkap bahwa daya saing pariwisata Indonesia masih rendah dibandingkan dengan negara-negara lain, termasuk dengan negara tetangga, seperti Malaysia dan Thailand; dan belum menjadikan pariwisata Indonesia sebagai destinasi pariwisata yang mampu bersaing, baik di tingkat regional maupun internasional. Keterbatasan persediaan jumlah, jenis, dan kualitas sumber daya manusia di bidang pariwisata juga turut menjadi salah satu kelemahan daya saing Indonesia, kemudian pengelolaan destinasi wisata yang masih kurang optimal menambah rapor merah bagi penilaian daya saing destinasi pariwisata Indonesia. Dukungan akan sarana dan prasarana sebagai faktor pendukung pariwisata serta minimnya ketersediaan fasilitas umum yang layak juga turut menjadi kendala dan menjadikan pariwisata Indonesia belum siap bersaing secara global. Porter (2008) menjelaskan pentingnya daya saing karena tiga hal berikut: (1) mendorong produktivitas dan meningkatkan kemampuan mandiri, (2) dapat meningkatkan kapasitas ekonomi, baik dalam konteks regional ekonomi maupun kuantitas pelaku ekonomi sehingga pertumbuhan ekonomi meningkat, (3) kepercayaan bahwa mekanisme pasar lebih menciptakan efisiensi.

Berdasarkan latar belakang tersebut, maka perumusan masalah pada penelitian ini adalah bagaimana hasil analisa pada sebuah jurnal yang berjudul "Measuring Destination Competitiveness: An Application of the Travel and Tourism Competitiveness Index (2007)", bagaimana perbandingan daya saing pariwisata
Indonesia dengan daya saing pariwisata negaranegara yang terdapat pada jurnal "Measuring Destination Competitiveness: An Application of the Travel and Tourism Competitiveness Index (2007)", dan apa yang harus dilakukan pariwisata Indonesia agar dapat meningkatkan daya saing pariwisatanya sehingga dapat bersaing secara global.

Penelitian ini, bertujuan dengan hasil analisis pada jurnal yang berjudul "Measuring Destination Competitiveness: An Application of the Travel and Tourism Competitiveness Index (2007)" maka dapat mengetahui posisi Indonesia apabila dibandingkan dengan negaranegara yang berada di jurnal terkait kemudian langkah apa saja yang dapat diambil Indonesia untuk meningkatkan daya saing pariwisata Indonesia. Penelitian ini dibatasi agar lebih fokus dan terarah. Penelitian dilakukan hanya menganalisis pada jurnal yang berjudul "Measuring Destination Competitiveness: An Application of the Travel and Tourism Competitiveness Index (2007)" dan menggunakan data dari hasil laporan "Measuring Travel and Tourism Competitiveness Index 2017 yang dikeluarkan oleh World Economic Forum.

\section{METODE PENELITIAN}

Penelitian dilakukan dengan menggunakan metode kualitatif yaitu studi kepustakaan. Studi kepustakaan adalah sebuah metode untuk menganalisis sebuah teks atau wacana untuk mengkaji hasil pemikiran dan penelitian seorang peneliti (Ibrahim 2015). Penelitian kepustakaan selalu identik dengan kegiatan analisis sebuah teks atau wacana. Analisis adalah penyelidikan terhadap suatu peristiwa, baik berupa perbuatan atau tulisan yang diteliti untuk mendapatkan fakta yang tepat, untuk menemukan konsep atau teori yang terkandung di dalamnya. Studi kepustakaan dilakukan dengan beberapa langkah berikut: (1) identifikasi permasalahan, (2) landasan teori, (3) penetapan maksud penelitian, (4) pengumpulan data, dan (5) analisis dan interpretasi data. Adapun data yang digunakan adalah data sekunder yaitu dengan menganalisis jurnal yang berjudul "Measuring Destination Competitiveness:An Application of The Travel and Tourism Competitiveness Index (2007)" yang ditulis oleh Cagil Hale Kayar dan Nazmi Kozak tahun 2010 dan laporan Travel 
and Tourism Competitiveness Index (2017) yang dikeluarkan oleh World Economic Forum.

\section{HASIL PENELITIAN}

\subsection{Hasil Studi Pustaka Jurnal "Measuring Destination Competitiveness: An Application of The Travel and Tourism Competitiveness Index (2007)"}

Jurnal yang dianalisis menggunakan studi kepustakaan adalah sebuah jurnal berjudul "Measuring Destination Competitiveness: An Application of The Travel and Tourism Competitiveness Index (2007)" yang ditulis oleh Cagil Hale Kayar dan Nazmi Kozak yang diterbitkan pada Journal of Hospitality Marketing and Management pada bulan maret tahun 2010. Latar belakang peneliti menuliskan jurnal ini adalah berangkat dari realita yang ada saatinibahwa sektor pariwisata menjadi sebuah leading sector bagi pembangunan ekonomi sebuah negara. Penerimaan devisa dari sektor pariwisata di berbagai negara dari tahun ke tahun selalu mengalami peningkatan. Hal ini menggambarkan bahwa pariwisata antar negara saling bersaing untuk mendapatkan pendapatan dari sektor ini, sehingga destinasi wisata yang ada di suatu negara dinilai sangat memerlukan keunggulan daya saing tersendiri sehingga dapat menarik wisatawan. Porter (1990) mengatakan bahwa keunggulan daya saing pariwisata meningkat secara siginifikan.

Potensi suatu negara dalam mengembangkan keunggulan daya saing pariwisatanya dapat dilakukan dengan meningkatkan kemampuannya dalam memelihara keunggulan daya saing itu sendiri, seperti pada saat pengiriman barang dan pelayanan pada para wisatawan. Studi literature sudah banyak yang mengukur keunggulan daya saing sebuah destinasi menggunakan bukti sampel dari data institusi pariwisata internasional atau nasional. Studi lainnya juga ada yang menggunakan pendekatan ini dan merancang pariwisata dengan menggunakan data ini sebagai data primer. Namun, kebanyakan dari penelitian ini mengalami kegagalan dalam menemukan faktor-faktor daya saing berdasarkan perspektif bagaimana faktor-faktor ini secara efektif menentukan posisi sebuah destinasi yang memiliki daya saing. Terjadi sebuah gap studi kuantitatif dalam menstratifikasikan faktorfaktor daya saing (kompetitif). Hal ini membuat peneliti yang melihat sebuah gap, melakukan penelitian dengan tujuan untuk mengetahui bagaimana daya saing negara-negara yang berada di dalam EU (Europe Union) dan Turki berdasarkan 13 faktor yang menjadi indikator pada hasil laporan The Travel and Tourism Competitiveness Index 2007 dan melakukan stratifikasi untuk mengetahui faktor daya saing mana yang paling efektif dalam memposisikan sebuah destinasi menjadi destinasi yang berdaya saing. Adapun hal-hal yang dianalisis dalam jurnal ini sebagai berikut:

1. Bagaimana Negara-negara ini di klusterisasikan dari hasil skor daya saing yang dimiliki masing-masing negara berdasarkan ke-13 faktor pada Travel and Tourism Competitiveness Index 2007 dan mengilustrasikan posisi daya saing tersebut?

2. Bagaimana menstratifikasi ke-13 faktor daya saing berdasarkan derajat keefektifan keunggulan daya saing dari negara-negara tersebut ?

3. Bagaimana posisi Turki pada pasar pariwisata internasional dan saran apa untuk Turki untuk menanggulangi kelemahannya?

Data yang digunakan pada jurnal ini adalah data sekunder pada laporan Travel and Tourism Competitiveness index 2007. Metode penelitian yang digunakan adalah teknik analisis kluster. Teknik analisis kluster adalah sebuah teknik mengelompokkan data menjadi kelompokkelompok data sehingga di dalam satu kelompok data memiliki karakteristik data yang homogen. Teknik analisis cluster ini akan mengklusterisasikan 28 negara yang memiliki daya saing yang sama berdasarkan ke-13 faktor competitiveness yang diambil dari laporan The Travel and Tourism Competitiveness Index 2007. Faktor-faktor yang digunakan dalan penelitian ini adalah Policy Rules and Regulations, Environmental Regulation, Safety and Security, Health and Hygiene, Prioritization of Travel and Tourism, Air Transport Infrastructure, Ground Transport Infrastructure, Tourism Infrastructure, Information and Communication Technology (ICT) Infrastructure, Price Competitiveness in the Travel and Tourism Industry, Human Resources, National Tourism Perceptions, and Natural and Cultural Resources. Faktor-faktor ini yang terdapat pada The Travel and Tourism 
Competitiveness Index 2007 digunakan sebagai indikator untuk mengukur daya saing suatu destinasi karena indikator ini dinilai dapat menjadi bahan untuk mengevaluasi kemampuan daya saing suatu destinasi di beberapa negara dalam jurnal ini.

Data analisis dilakukan dengan dua langkah. Langkah pertama adalah mengklusterisasikan ke-28 negara berdasarkan ke-13 faktor daya saingnya, sehingga negara-negara yang memiliki faktor daya saing yang sama atau terdapat kemiripan akan berada pada satu kluster yang sama. Langkah kedua yaitu melakukan multidimensional scalling digunakan untuk mengidentifikasi keefektifan sebuah faktor daya saing. Berdasarkan ke-13 faktor daya saing tersebut mana yang paling efektif dan mana yang paling rendah nilai efektivitasnya.

Hasil dari penelitian ini adalah peneliti berhasil mengklusterkan ke-28 negara menjadi tiga (3) kluster. Kluster pertama terdiri dari 8 negara yaitu; Bulgaria, Latvia, Lithuania, Hungaria, Polandia, Romania, Slovakia, dan Turki. Kluster kedua terdiri dari 9 negara yaitu; Austria, Jerman, UK, Denmark, Perancis, Finlandia, Swedia, Belanda, dan Belgia. Kluster ketiga terdiri dari 11 negara yaitu; Republik Ceko, Estonia, Irlandia, Malta, Slovenia, Luxemburg, Spanyol, Cyprus, Portugal, Yunani, dan Italia. Berdarkan hasil klusterisasi, pada kluster 2 faktor-faktor daya saing yang paling efektif adalah Policy and Rules Regulation, Environmental Regulation, Safety and Security, Health and Hygiene, Air Transport Infrastructure, Ground Transport Infrastructure, ICT Infrastrucure, Human Resource and Natural and Cultural Resources. Pada kluster 3, faktor-faktor daya saing yang paling efektif adalah Prioritization of Travel and Tourism, Tourism Infrastructure and National Tourism Perceptions. Pada kluster 1, faktor yang memliki nilai tertinggi adalah Price competitiveness in Tourism.

Kluster 2 menunjukkan tingkat efektivitas tertinggi berdasarkan faktor-faktor daya saing yang dimiliki oleh negara-negara yang berada pada kluster 2 yaitu Austria, Jerman, UK, Denmark, Perancis, Finlandia, Swedia, Belanda, dan Belgia. Faktor-faktor daya saing yang paling efektif pada kluster 2 adalah Air Transport Infrastructure, natural and Cultural Resources, Ground Transport Infrastructure, and Health and Hygiene. Sedangkan faktor daya saingyang memberikan tingkat efektivitas peringkat kedua adalah Environmental Regulation, ICT Infrastructure, Safety and Security, and Policy Rules and Regulations. Negara-negara pada kluster 2 ini memiliki keunggulan daya saing sehingga destinasi mereka berhasil memasuki pasar pariwisata internasional.

Negara-negara yang berada pada kluster 3 yaitu Republik Ceko, Estonia, Irlandia, Malta, Slovenia, Luxemburg, Spanyol, Cyprus, Portugal, Yunani, dan Italia ini memiliki hubungan yang baik diantara negaranya, sehingga pada kluster ini tingkat efektivitas faktor-faktor seperti Tourism Infrastructure, The Prioritization of Travel and Tourism and National Tourism Perception menempati posisi yang paling efektif. Hal ini dibuktikan dengan adanya keunggulan di dalam infrastruktur pariwisatanya di masing-masing negaranya. Hal ini membuat negara-negara yang terdapat dalam kluster 3 lebih memiliki daya tarik pada investasi pribadi di industri, keikutsertaan pada International Tourism and Travel Exhibition dan mempromosikan daya tarik destinasinya.

Price competitiveness di dalam industry perjalanan dan pariwisata memberikan pengaruh yang minimum terhadap daya saing. Nilai Price Competitiveness paling tinggi berada pada kluster 1 yang dimana hal ini menunjukkan bahwa negara-negara yang berada pada kluster 1 yaitu Bulgaria, Latvia, Lithuania, Hungaria, Polandia, Romania, Slovakia, dan Turki memiliki keunggulan daya saing Price Competitiveness. Indikator yang terdapat pada Price Competitiveness adalah harga rendah dan peningkatan daya tarik suatu negara bagi turis. Turki memiliki reputasi destinasi wisata murah, sehingga hal ini sesuai dengan hasil yang dimana negara-negara yang terdapat pada kluster 1 merupakan negaranegara yang memiliki lower middle income terhadap perekonomian di negaranya. Berdasarkan hal tersebut, Turki harus meningkatkan keunggulan daya saingnya terutama pada Air and Grounds Transport Infrastructure, Natural and Cultural Resource, atau Health and Hygiene.

Terdapat banyak gap pada keunggulan daya saing pariwisata yang terjadi antara Turki dan negara-negara yang berada dalam EU (Europe Union). Turki harus memiliki keunggulan daya 
saingnya yang dapat dikembangkan melalui ICT dan sumber daya manusia. Turki harus menjadi benchmark tersendiri bagi negaranegara lain dibandingkan hanya dengan memiliki citra sebagai negara dengan harga destinasi murah.

\subsection{Peningkatan Daya Saing Pariwisata Indonesia Berbasis Travel and Tourism Competitiveness Index}

Indonesia berada pada posisi ke-42 di dalam The Travel and Tourism Competitiveness Index 2017, walaupun sebelumnya pada tahun 2015 Indonesia berada posisi ke-50. Kenaikan terjadi sebanyak 8 peringkat. Hal ini menunjukkan sebuah usaha dari Indonesia untuk selalu meningkatkan daya saing pariwisatanya. Berdasarkan hasil dari Travel and Tourism Competitiveness Index 2017, faktor daya saing yang paling efektif bagi Indonesia adalah Price Competitiveness. Indonesia masih memiliki citra sebuah negara dengan harga destinasi termurah dibandingkan negara-negara lainnya sehingga Price Competitiveness disini menjadi faktor daya saing yang unggul. Namun apabila dibandingkan dengan hasil studi kepustakaan pada Kayar dan Kozak (2017) menunjukkan bahwa Price Competitiveness adalah faktor daya saing yang memiliki pengaruh paling minimum terhadap efektifitas nilai daya saing.

Kemudian, faktor-faktor daya saing kedua yang memiliki nilai efektivitas bagi Indonesia adalah Safety dan Security dan Prioritization of Travel and Tourism, Natural Resource, Human Resource and Labour Market, Bussiness Environment, Health and Hygiene, International Opennes adalah faktor-faktor daya saing Indonesia yang menduduki peringkat ke-3 dalam memberikan pengaruh terhadap keefektivitasan daya saing. Indonesia memerlukan perbaikan dan pembangunan pada faktor-faktor ICT Readiness, Air Transportation Infrastructure, Environmental Sustainability, Ground and Port Infrastructure, dan Tourist Service Infrastructure. Faktorfaktor tersebut memiliki nilai terendah di dalam 14 faktor yang terdapat di Tourism and Travel Competitiveness Index 2017.

\section{SIMPULAN}

Hasil studi kepustakaan pada jurnal "Measuring Destination Competitiveness: An Application of The Travel and Tourism
Competitiveness Index (2007)" telah mengklusterisasikan ke-28 negara menjadi 3 kluster. Kluster 1 yang terdiri dari negara yaitu Bulgaria, Latvia, Lithuania, Hungaria, Polandia, Romania, Slovakia, dan Turki memiliki Price Competitiveness sebagai faktor daya saing tertinggi yang paling ef ektif. Namun dalam hal ini Price Competitiveness diantara faktor daya saing lainnya merupakan faktor yang paling minimum efektivitasnya. Sehingga negara-negara yang berada dalam kluster ini, terutama negara Turki harus melakukan beberapa perbaikan untuk meningkatkan daya saing. Peningkatan daya saing dapat dilakukan dengan melihat indikator mana dari faktorfaktor daya saing y ang memiliki skor terendah seperti pada Air and Grounds Transport Infrastructure perlu melakukan pembangunan infrastruktur jalan, pada Natural and Cultural Resource perlu memfokuskan pada bisnis berbasis ekosistem, dan Health and Hygiene perlu membangun fasilitas yang dapat meningkatkan akses sanitasi.

Kluster 2 yang terdiri dari Austria, Jerman,UK, Denmark, Perancis, Finlandia, Swedia, Belanda, dan Belgia merupakan negara yang paling ungguldalam memiliki faktor daya saing destinasi pariwisata. Faktor daya saing yang menjadi unggulan dan memiliki efektivitas tinggi adalah Air Transport Infrastructure, natural and Cultural Resources, Ground Transport Infrastructure, and Health and Hygiene. Sedangkan faktor daya saing yang memberikan tingkat efektivitas peringkat kedua adalah Environmental Regulation, ICT Infrastructure, Safety and Security, and Policy Rules and Regulations. Kluster 3 yang terdiri dari negara Republik Ceko, Estonia, Irlandia, Malta, Slovenia, Luxemburg, Spanyol, Cyprus, Portugal, Yunani, dan Italia memiliki hubungan yang baik antar negara dan mereka unggul dalam infrastruktur pariwisatanya sehingga memiliki daya Tarik untuk investasi pribadi di dalam industri, keikutsertaan pada International Tourism and Travel Exhibition dan mempromosikan daya tarik destinasi.

Indonesia sebagai negara berkembang juga harus memiliki daya saing destinasi pariwisata agar dapat memasuki pasar pariwisata internasional. Indonesia sudah cukup baik dalam upayanya meningkatkan keunggulan daya saing pariwisatanya, namun masih banyak hal yang perlu dibenahi agar Indonesia dapat 
memasuki pasar pariwisata internasional yang memiliki keunggulan daya saing. Berdasarkan hasil dari Travel and Tourism Competitveness Index 2017, Indonesia berada pada peringkat ke-42 dari 136 negara. Peningkatan daya saing dapat dilakukan dengan melihat indikator mana dari faktor-faktor daya saing yang memiliki skor terendah.

Faktor-faktor daya saing yang perlu diperbaiki oleh Indonesia diantaranya ICT Readiness, Air Transportation Infrastructure, Environmental Sustainability, Ground and Port Infrastructure, dan Tourist Service Infrastructure. Adapun implikasi manajerial untuk ICT Readiness adalah perlu perbaikan kecepatan jaringan internet dan perluasan jaringan internet agar di seluruh daerah Indonesia sudah terjangkau oleh internet, pada Air Tranportation Infrastructure perlu pembangunan bandara yang lebih luas, besar, dan memiliki fasilitas internasional di beberapa daerah di Indonesia agar dapat menampung jumlah wisatawan yang datang melalui bandara. Pemugaran dan pemeliharan juga perlu dilakukan pada situs warisan dunia yang berada di Indonesia, agar situs-situs warisan budaya peninggalan kerajaan di masa lampau dapat dijadikan sebuah situs warisan dunia sehingga jumlah situs warisan dunia yang berada di Indonesia dapat meningkat. Indonesia juga perlu melakukan perawatan dan penanggulangan pada environmental sustainability terutama dalam penanggulangan air limbah. Perbaikan pada ground and port Infrastructure perlu adanya pembenahan pada sistem kereta api yang terintegrasi. Pembangunan pada Tourist Service Infrastructure perlu melakukan upaya perbaikan pada kamar hotel yang bersih, nyaman, dan aman.

\section{DAFTAR PUSTAKA}

[BPS] Badan Pusat Statistik. 2015. Jumlah Kunjungan Wisatawan Mancanegara 2015-2018 [Internet]. [diakses 2019 Oktober 1]. Tersedia pada: http//www.bps.go.id

Ibrahim. 2015. Metodologi Penelitian Kualitatif. Bandung (ID): Alf abeta.

Kasali, Rhenald. 2005. Manajemen Public Relations Konsep dan Aplikasinya di Indonesia. PT Pustaka Utama Grafiti.Jakarta

Kayar, Hale Cagil dan Kozak, Nazmi. 2010. Measuring Destination Competitiveness: An Application of the Travel and Tourism Competitiveness Index (2007). Journal of Hospitality Marketing and Management. Vol 19(3) : 203-216.

Michael E. Porter. 1990. Competitive Strategy, Techniques for Analysing Industries and Competitors., New York (USA): The Free Press.

Michael E. Porter. 1995. "Competitive Advantage'New York (USA): The Free Press. edisi terjemahan (2008): Kharisma Publishing Group.

Michael R. Baye. 2010. Managerial Economic and Business Strategy7th ed: McGrawHill.

World Economic Forum. 2007. Travel and Tourism Competitiveness Index Report. Geneva $(\mathrm{CH})$

World Economic Forum. 2017. Travel and Tourism Competitiveness Index Report. Geneva $(\mathrm{CH})$ 